\title{
"ELECTRONIC VOTING SYSTEM USING AUTOMATED BIOMETRIC VOTER AUTHENTICATION SYSTEM"
}

\author{
Nitin D.V. \\ P.G. Student \\ Industrial Automation and Robotics \\ Department of Mechanical Engineering \\ Malnad College of Engineering, Hassan, Karnataka, \\ India
}

\begin{abstract}
Election process is a most sensitive event in all democratic countries hence it as its own importance in view of its smooth and secure conduction. In this respect the present work is a proposal of electronic voting system that includes multiple layer of authentication so that will help to eradicate problems such as proxy voting, fraud voting and rigging. Authentication is done using a biometric that is finger print sensor. The voting is done manually by pressing the push buttons for their respective candidates. This is done only after the voter is verified by the database which as stored information i.e. biometrics of enrolled voters.
\end{abstract}

Keywords - Electronic voting system, Finger print module, Arduino UNO, LCD

\section{INTRODUCTION}

In a democratic countries where the people's representatives are elected by the process called election. Elections involve public or private depending upon the position they are contesting i.e. local, state and centre.

In early practice i.e. post independence voting was done by paper based mode commonly called ballet voting. In paper based process after the voter identification is verified by the officials then the voters are given a ballot paper and then asked to vote for their respective candidate and ballot paper is deposited in a box (Deepika et al., 2016). During results, ballot paper boxes are opened and votes are counted manually in presence of election officials. But this method had lot of limitations such as more manual work, required more man power to conduct this process, also chances of error in counting the votes and in some cases multiple votes in a single paper which becomes a invalid vote (P.Bhavani Sankar et al., 2018). There were also chances that votes may be manipulated to distort the result in favour of certain candidates.

To overcome these disadvantages some countries introduced direct recording electronic machine commonly called as

\author{
B. S. Shivashankara \\ Assistant Professor \\ Industrial Automation and Robotics \\ Department of Mechanical Engineering \\ Malnad College of Engineering, Hassan, Karnataka, \\ India
}

electronic voting machine. This EVM is simple in design, easy to use and reliable. Even though it is a simple process but the major challenge is rigging. In this process also proxy voting would take place lot of methods are implemented to eradicate these problems but not able eradicate completely, hence the proposed system which is based on biometric can overcome these disadvantages.

Biometric is nothing but analysing the biological data i.e. human body characteristics such as voice patterns, facial patterns, eye retina and iris, finger print (Rudrappa B. Gujanatti et al., 2015) (M. Sudhakar et al., 2015).This project is done with finger print identification system, since each individual as unique finger print and hence this plays a major role in authenticating the right individuals.

Existing electronic voting machine was introduced to eradicate the faults which occurred in ballot voting method. But in this electronic voting machine method rigging is the major disadvantage where unknown persons can do proxy voting, in case, if the voters identity was not crosschecked properly by human errors.

This work proposes biometric for authenticating as each individual as unique finger print. It helps in minimizing the error. A data base is created for each individual voter. This makes EVM system in election, a fair and free from rigging and other disadvantages mentioned above.

\section{METHODOLOGY}

The system aims in developing a secure electronic voting system using fingerprint technique, which helps in free and fair mode of conducting the election which is required in democratic countries. This proposed electronic voting machine consists of finger print module, control unit, liquid crystal display, power supply. In pre election process, voters enrollments need to be done i.e. voters finger print need to be enrolled. During election the voters need to authenticate their identity, if they are verified then they are allowed to cast their 
vote. If the finger print matches the finger which is stored in database then it is validated and verified. In LCD it displays the message called please cast your vote, then the voter need to vote his choice of candidate. If unregistered or the person who was not enrolled and comes to cast his vote then on LCD message is displayed as "invalid voter". Here by this a proxy voter can be found. If in other case a person who has voted comes to vote again then on LCD message is displayed as "already voted". Finally, after all the registered people votes then on LCD display, it can be found that, who has got how many votes. The block diagram of the proposed voting system is as shown in the following figure 1.

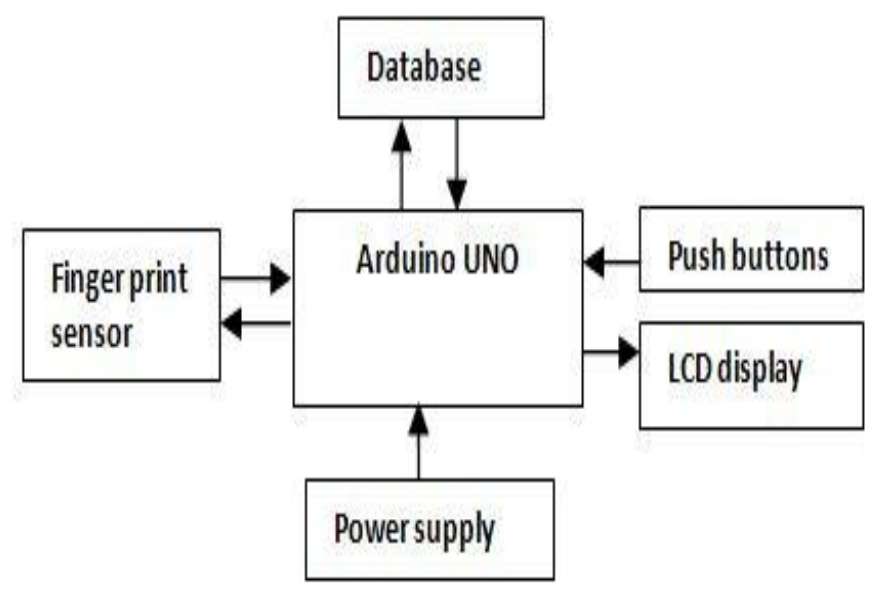

Fig.1. Block diagram of finger print based electronic voting machine.

The process basically consists of two modes
a. Voter enrollment
b. Vote casting

\section{A. Voter Enrollment -}

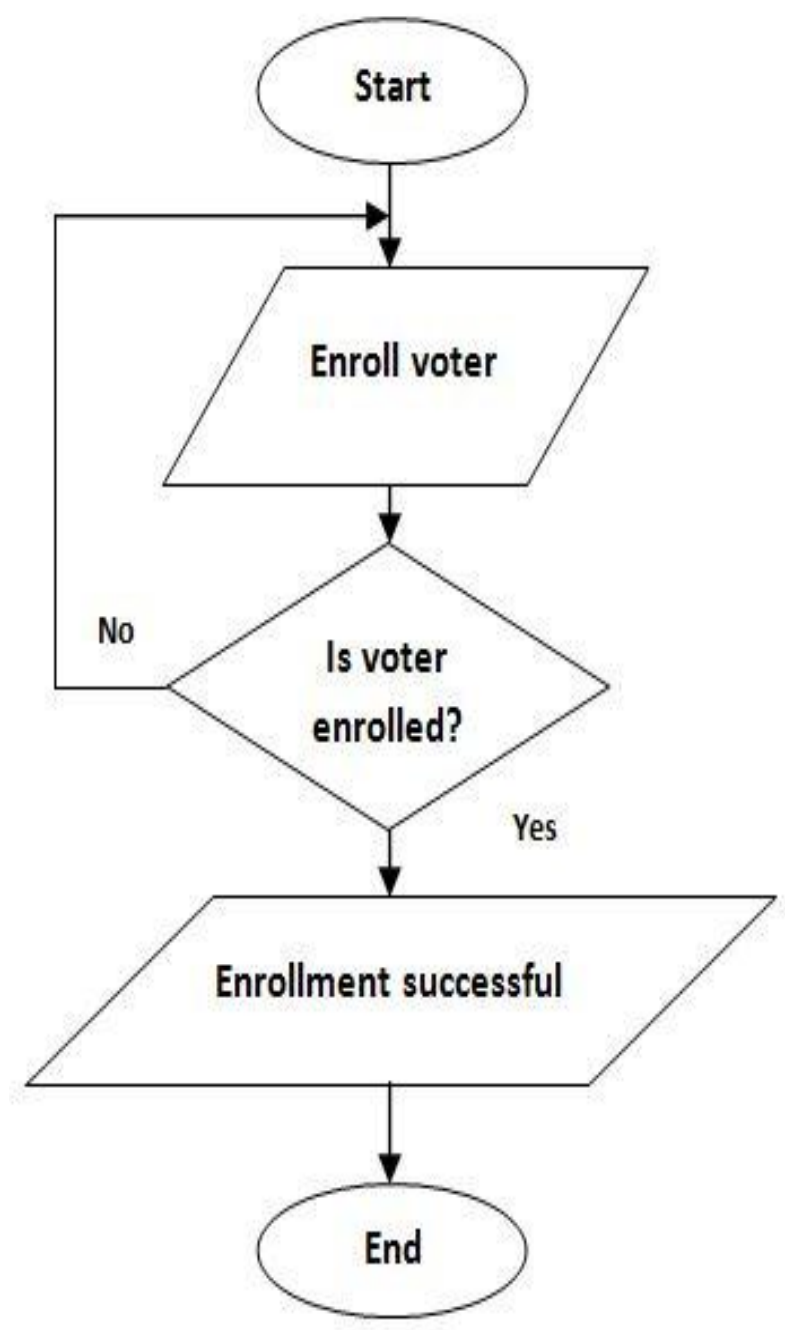

Fig.2. Voter enrollment process

This process can also be called as pre election process fig-2 where the voter's fingerprints are loaded into database of the system. Voter's enrollment can be done by pressing the enrollment push button and LCD displays a message called place finger for enroll. Same finger need to be placed thrice so that voter is enrolled. Suppose if there is any error in placing the finger then it displays a error message if it is successful then the voter is enrolled. This process is only accessible by the election commission or electoral officials.

\section{B. Vote Casting -}


International Journal of Engineering Applied Sciences and Technology, 2019

Vol. 4, Issue 2, ISSN No. 2455-2143, Pages 160-163

Published Online June 2019 in IJEAST (http://www.ijeast.com)

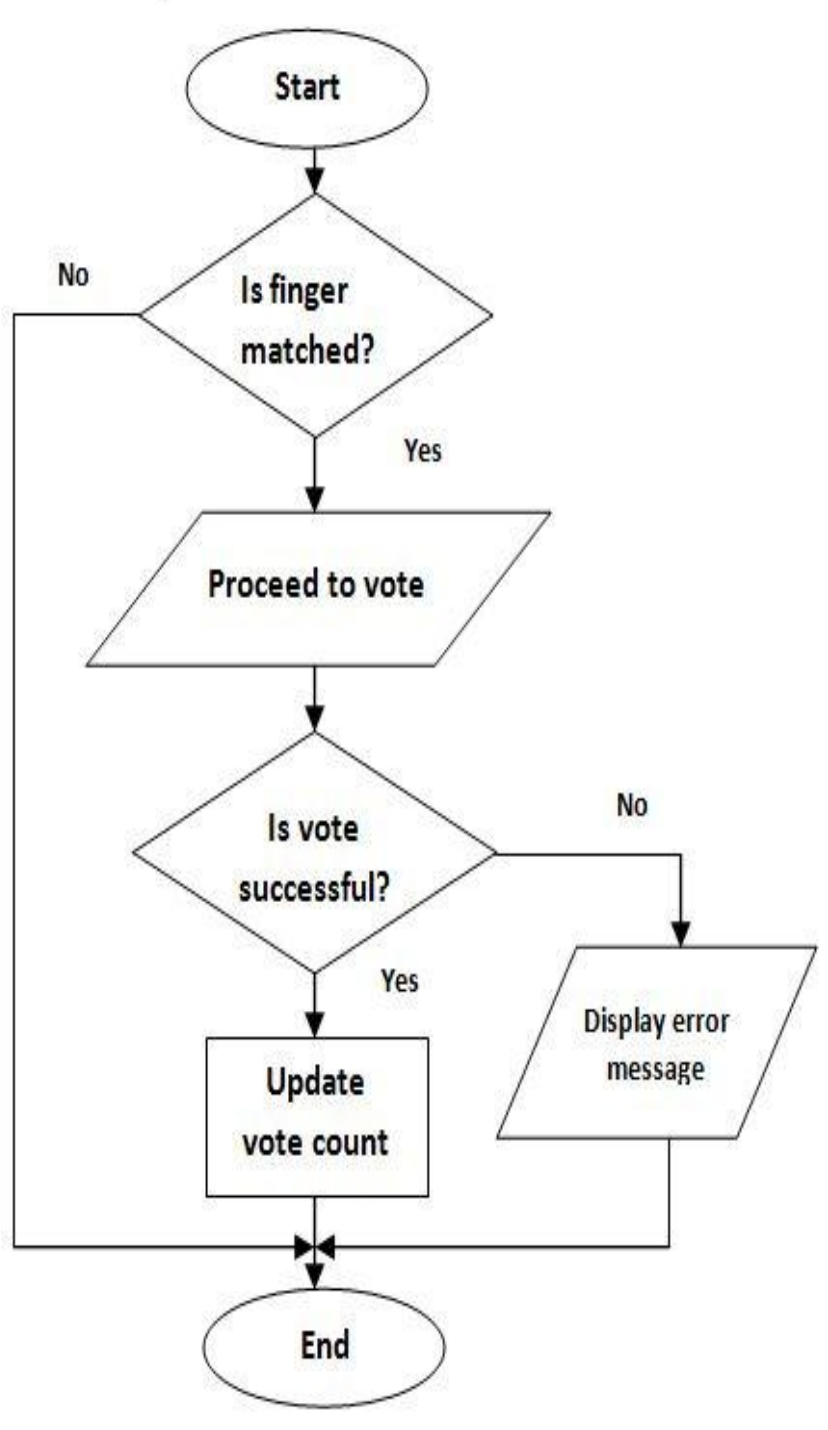

Fig.3. Vote casting process

In this process fig-3, the voter is allowed to prove his identity by verifying and validating his biometric. If the voter is enrolled person, then it displays a message to cast his vote. If the person is not enrolled and comes to vote, biometric mismatched with that of database then it shows a error message on the LCD called invalid voter and not allowed to cast their vote. Suppose a same person who has already voted comes to vote again then during authenticating process it displays a error message as already voted and does not allow to cast his/her vote. Only the authenticated votes are updated for counting.

\section{EXPERIMENT AND RESULT}

\section{Voter enrollment}

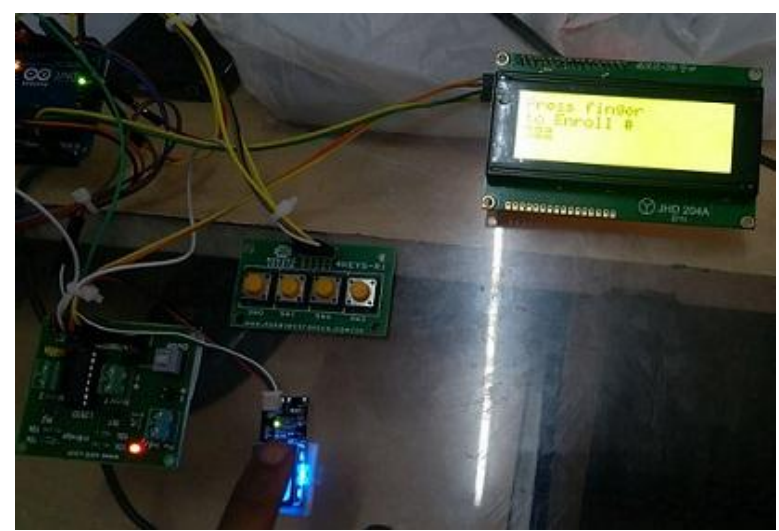

Fig -4: Enrolling the voter

2. Enrollment successful

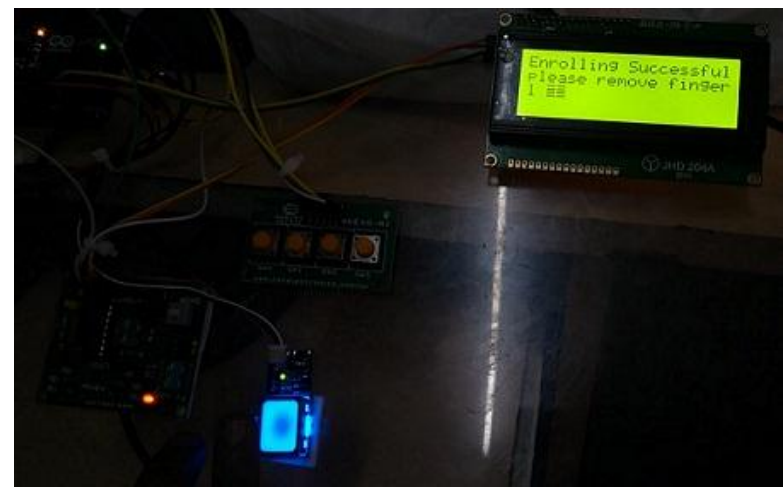

Fig -5: Voter enrollment successful

3. Authentication of voter

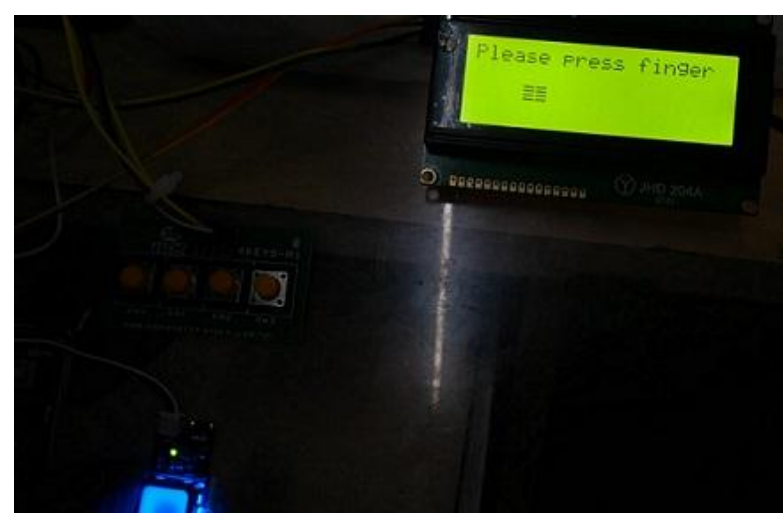

Fig -6: Voter authentication 


\section{Casting of vote}

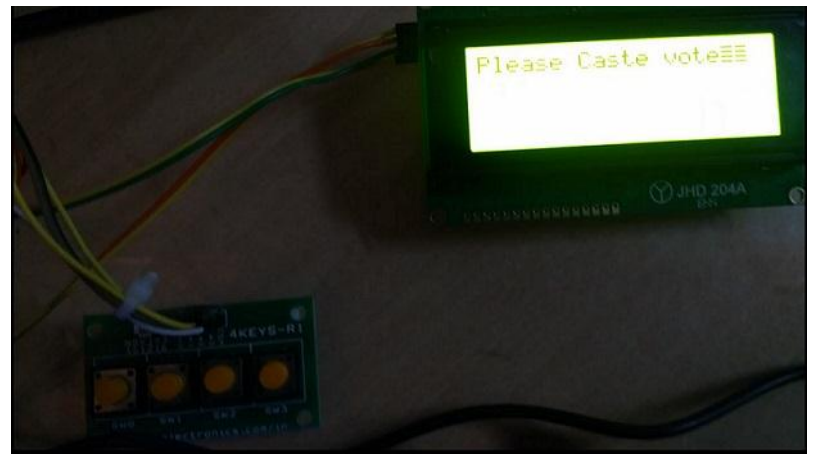

Fig -7: Casting of vote

5. Re-voting of same person

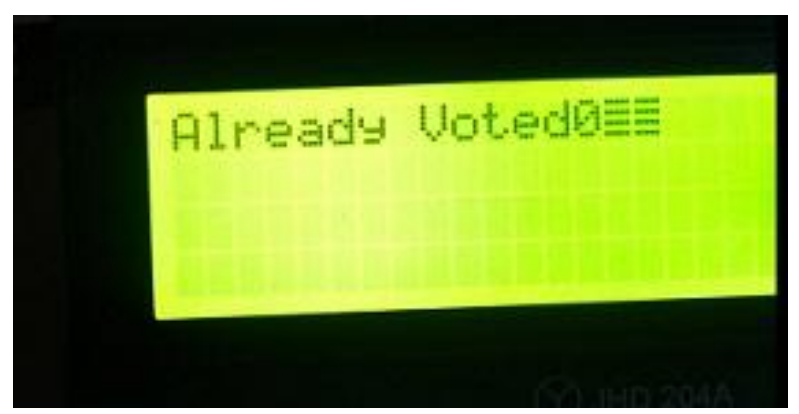

Fig -8: Message on LCD of re-voter

the entire process of voters enrollment, his authentication and casting of vote using a proposed biometric based electronic voting system is shown step by step as shown in fig 4 to fig 8 .

\section{CONCLUSION}

This biometric based voting system provides full security for authentication as fingerprint module is used, where every individual as different biometric. This system overcomes the challenges faced by other conventional election method such as rigging. The proposed method helps in secure elections and saves time and requires less man power for conducting electoral process, as a fault proof and reliable process.

\section{REFERENCE}

[1] S. Aadhithyan and P. Tamilarasu (2018), "Fingerprint Based Electronic Voting Machine", Technical Research Organization India, ISSN: 2393-8374, Vol. 05, Issue-02, 2018.

[2] P.Bhavani Sankar and CH.S. Vineetha Devi (2018), "Finger Print Based Electronic Voting Machine", International Research Journal of Engineering and
Technology (IRJET), Vol. 05, Issue-02, Feb-2018, pp.1040-1042

[3] Deepak Rasail,Jigmee Sherpa, Yashal Dorzee Lepcha (2016), "Design of Electronic Voting Machine using Microcontroller", International Journal of Engineering Trends and Technology, ISSN: 2231,Vol-32 issue 5,2016, pp.277-278.

[4] Deepika, Iswarya, Rathna Prabha, Trini Xavier (2016), "A Survey on E-Voting System Using Arduino Software" International Journal of Advanced Research in Electrical, Electronics and Instrumentation Engineering (An ISO 3297: 2007 Certified Organization) Vol. 5, Issue 2, February 2016, pp.687-690.

[5] Rudrappa B. Gujanatti (2015), “A Finger Print based Voting System", International Journal of Engineering Research \& Technology (IJERT),Vol. 04, Issue-05,May2015, pp.887-892.

[6] Balkrushna Bhagwatrao Kharmate, Shahebaz Shakil Shaikh, Prashant Ravindra Kangane, Tushar Anant (2015), “A Survey on Smart E-Voting System Based On Fingerprint Recognition", International Journal of Innovative Research in Computer and Communication Engineering, Vol. 3, Issue-9, September 2015, pp.80938100 .

[7] B. Divya Soundarya Sai, M. Sudhakar (2015), "Biometric System Based Electronic Voting Machine Using Arm9 Microcontroller", IOSR Journal of Electronics and Communication Engineering (IOSR-JECE) e-ISSN: 2278-2834,p- ISSN: 2278-8735.Vol.10, Issue 1,2015, pp.57-65.

[8] Aranganadhan. N. S, M. DhineshKumar, Praveenkumar. DSanthosh.A (2016), "Embedded System based Voting Machine System using Wireless Technology", International journal of innovative research in electrical instrumentation and control engineering, Vol. 4, Issue 2,2016, pp.127-130.

[9] Md. Asfaqul Alam, Md. Maminul Islam, Md. Nazmul Hassan, Md. SharifUddin Azad (2014), “ Raspberry Pi and image processing based Electronic Voting Machine (EVM)", International Journal of Scientific \& Engineering Research, Vol.5, Issue 1,2014,pp.1506-1510.

[10] D. Krishna (2013), "Aadhar Based Electronic Voting System and Providing Authentication" International journal of engineering and advanced technology, ISSN:2250- 3676,Vol.4,Issue 2,2013, pp.237-240.

[11] Diponkar Paul, Sobuj Kumar Ray, "A Preview on Microcontroller Based Electronic Voting Machine", International Journal of Information and Electronics Engineering, Vol. 3,2013, pp.185-190.

[12] Gomathi. B, Veena priyadarshini. S, "Modernized Voting Machine using Finger Print Recognition", International Journal of Scientific \& Engineering Research, Vol.4, Issue 5, ISSN 22295518,2013, pp.156-161. 